\title{
Role of Maize Weevil, Sitophilus zeamais Motsch. on Spread of Aspergillus section flavi in Different Nepalese Maize Varieties
}

\author{
K. Bhusal (iD) and D. Khanal (iD \\ Institute of Agriculture and Animal Sciences, Kirtipur, Kathmandu, Nepal \\ Correspondence should be addressed to D. Khanal; dipakbabu@hotmail.com
}

Received 10 September 2018; Revised 25 January 2019; Accepted 4 April 2019; Published 16 April 2019

Academic Editor: Innocenzo Muzzalupo

Copyright ( $) 2019$ K. Bhusal and D. Khanal. This is an open access article distributed under the Creative Commons Attribution License, which permits unrestricted use, distribution, and reproduction in any medium, provided the original work is properly cited.

Experiments were conducted to find out the role of maize weevil, Sitophilus zeamais Motsch. on spread of green fungus, Aspergillus section flavi, in different varieties of stored maize in laboratory in 2016. Lab experiment was conducted to find the role of weevil on spread of A. flavus on five main varieties of maize grown at Nepal in split plot design, namely, Arun-2, Arun-4, Manakamana-1, Manakamana-3, and Rampur composite with three replications at NAST, Khumaltar, from August to September 2016. One hundred grams of each maize variety was exposed to weevil along with fungus and with fungus only to see the spread of the fungus under presence and absence of weevil. Among the tested five maize varieties, the lowest infestation was observed on Rampur Composite (14.99\%) while it was the highest on Manakamana-3 (87.70\%). The highest mean infestation (75.58\%) was found under weevil released condition while it was lower (62.16\%) under nonreleased condition. In presence of weevil, the infestation of the fungus increased and in their absence the infestation was low which signifies the role of weevil in fungal spread. All indices indicate that Rampur composite is the best variety among the five tested varieties in terms of storage under the presence of fungus and weevils. This study also indicates ample scope for further study on different varieties of maize under several storage conditions.

\section{Introduction}

Maize (Zea mays L.), belonging to the family Poaceae or Gramineae, is a kind of grass related to rice, wheat, barley, and oat, ranking second in area cultivated and first in production and productivity in order of world grain production [1]. It is popularly known as queen of cereals, because of very high yield potential than any other cereals [2]. In Nepal, maize is grown in 882,395 ha of land with an average yield of $2.43 \mathrm{t} / \mathrm{ha}$ [3] which seems to be very low as compared to neighboring countries.

Insects are most often considered as the principal cause of maize grain losses [4]. Postharvest loss is a measurable quantitative, qualitative loss across the supply chain, or the postharvest system, from the time of harvest till its consumption $[5,6]$. Postharvest loss of maize has been estimated to be between $15 \%$ and $26 \%$ [7]. The greatest portions of these losses occur in the standing crops and during storage and are mainly due to insect infestation. Among insect pests, maize weevil (Sitophilus zeamais Motsch.) and Angoumois grain moth (Sitotroga cerealella) are the most important insects in stored maize in Nepal $[8,9]$. The most economically important and widely occuring postharvest losses due to insect pests of stored maize include the maize weevil (Sitophilus zeamais Motsch.), a ij inch long, and reddish brown to black snout weevil pests of stored maize include the maize weevil [10].

S. zeamais Motsch. is one of the most serious, internal feeding pests of maize. It is among the most destructive pests in stored grain, especially corn in tropical regions [11]. Adult female of weevils causes damage by boring into the kernel and laying eggs (ovipositing). Then, larvae and pupae eat the inner parts of the kernel, resulting in a damaged kernel, and reduced grain weight [12]. The infestation elevates temperature and moisture content in the stored grain mass, which can lead to fungal growth, including toxigenic species such as Aspergillus flavus Link. [13].

Aspergillus flavus is a saprophytic soil fungus that infects and contaminates preharvest and postharvest seed crops like cereals, legumes, and oil seeds [14]. The species, A. flavus, 
belongs to the Genus Aspergillus, Subdivision Deuteromycotina [15]. This species grows on a wide range of agricultural commodities that include peanuts, dried corn, millet, tree nuts, and cotton seeds [16] and leftover foods such as rice. $S$. zeamais cause extensive losses in quantity and quality of the grain in the field as well as in storage [17]. Numerous insect species have been implicated in facilitating the dispersal of $A$. flavus and subsequent aflatoxin contamination [18, 19]. The spread of the green fungus in maize seed is a great problem in stored maize and the metabolic activities of weevil linked in the spread of spores of the fungus are a major reason for the research.

\section{Materials and Methods}

2.1. Laboratory Experiment. The experiments were conducted in Natural Products Research Laboratory of Nepal Academy of Science and Technology (NAST), Khumaltar, Lalitpur, starting from June to September 2016.

2.1.1. Cleaning, Drying, and Sterilization of the Seed. The seeds of five different maize varieties, namely,Manakamana3, Manakamana-1, Arun-2, Arun-4, and Rampur composite collected from Nepal Agricultural Research Council (NARC), Rampur, Chitwan, were cleaned thoroughly to be free from dust, dirt, stubbles, and foreign matter and dried in the sun to reduce the moisture level of seed. The moisture level was maintained from 11 to $12 \%$. Cleaned and dried seeds were filled on the steel container and kept on the hot air oven at $70^{\circ} \mathrm{C}$ for 2 days to sterilize the seed and make it free from pathogens and weevils. The pathogen was eliminated from maize seeds treated at $60^{\circ} \mathrm{C}$ for 15 days or at $70^{\circ} \mathrm{C}$ for 2 days and germination rates in most samples were not affected [20].

2.1.2. Mass Rearing of Weevil, Isolation, and Culture of Fungus. Live insect specimens of S. zeamais were collected from Nepal Agricultural Research Council (NARC), Khumaltar, Lalitpur. Manakamana-1 variety of maize was used for insect rearing. Hundred pairs of one-week-old S. zeamais were introduced into $2 \mathrm{~kg}$ grains of maize in $6.5 \mathrm{~kg}$ capacity Kilner jars covered with mesh lids [21]. Infected maize cob was used for isolation of the fungus (A. section flavi). The fungus was transferred to the Potato Dextrose Agar (PDA) media with the help of sterilized inoculation loop. The media were placed on the incubator at $27^{\circ} \mathrm{C}$ for 5 days. Isolates were identified as $A$. section flavi based on colony characteristics, strain morphology, and microscopic features according to [22].

2.1.3. Inoculation of the Fungus and Insect. Five pairs of weevils were kept into the sterilized test tube of $5 \mathrm{ml}$ capacity. An inoculation loop was dipped in the pure culture of $A$. section flavi and was introduced into the same test tube containing the weevil and then plugged by the sterilized cotton plug. The tube was shaked so that the spores get in contact with the cuticle of the weevils. Those five pairs of weevil treated with spores of A. section flavi were released selectively on bottles with treatment numbers $1,2,3,4$, and 5 each containing 100 grams of different maize varieties, while in others same inoculation loop was dipped in the pure culture containing A. section flavi and was released on bottles with treatment numbers $6,7,8,9$, and 10 each containing 100 grams of different maize varieties only. The treatments numbers 1,2 , 3,4 , and 5 differ with treatment $6,7,8,9$, and 10 in terms of presence and absence of weevil only. The spore population in inoculation loop dipped in a pure culture was calculated by using spread plate technique [23]. Nearly an average spore number of $33 * 10^{\wedge}-3 \mathrm{CFU}$ was obtained. The 10 maize grains in the bootless were collected after 10, 12, 17, 19, 24, 26, 31, and 33 days after the inoculation of fungus and was viewed under microscope to check the infestation. The infestation percentage was calculated as follows:

$$
\begin{aligned}
\text { Infestation }(\%)= & \frac{\text { Number of infected seeds }}{\text { Total number of seeds per plate }} \\
& \times 100
\end{aligned}
$$

The resistance and susceptibility of the varieties against A. section flavi were categorized on the following scale given by [24]. Resistant $=$ Less than $15 \%$ seed infection.

Moderately resistant $=16-30 \%$ seed infection.

Susceptible $=31-50 \%$ seed infection.

Highly susceptible $=$ above $50 \%$ seed infection.

In samples, undamaged and damaged grains were counted and weighted separately and percentage loss was calculated as follows [25].

$$
\text { Weight loss }(\%)=\frac{(\mathrm{UNd})-(\mathrm{DNu})}{\mathrm{U}(\mathrm{Nd}+\mathrm{Nu})} \times 100
$$

where $\mathrm{U}$ is Wt. of undamaged grains, D is Wt. of damaged grain, $\mathrm{Nd}$ is No. of damaged grain, $\mathrm{Nu}$ is No. of undamaged grain.

In this method, recommended sample size is $100-1000$ grains.

The percentage of insect damaged seed was then calculated [26] as follows:

$$
\begin{aligned}
& \text { Insect damaged percentage }(\%) \\
& \qquad=\frac{\text { Number of insect damaged grain }}{\text { Total number of grain }} \times 100
\end{aligned}
$$

2.1.4. Experimental Design and Statistical Analysis. The experiment was laid out in split plot design with three replications. Two factors were included in the experiment. Five varieties of maize were treated as main factor and two levels of weevil, i.e., presence and absence of weevil, were treated as subplot factors. The data of each experiment was collected and analyzed by suitable Microsoft software package like RStat. The mean comparisons were done by DMRT at 5\% and $1 \%$ level of significance [27]. Regarding the software programs, Microsoft word 2007 was used for word processing. MS Excel was used for data entry, tables, and graphs preparation. 
TABLE 1: Infestation on different maize varieties by artificial inoculation of A. section flavi in vitro recorded from August to September, 2016.

\begin{tabular}{|c|c|c|c|c|c|c|c|c|c|}
\hline \multirow{4}{*}{ Maize varieties } & \multicolumn{8}{|c|}{ A. flavus infestation (\%) } & \multirow{4}{*}{ Grand Mean } \\
\hline & \multicolumn{8}{|c|}{ Days after inoculation } & \\
\hline & 10 & 12 & 17 & 19 & 24 & 26 & 31 & 33 & \\
\hline & days & days & days & days & days & days & days & days & \\
\hline \multirow{3}{*}{ Manakamana-3 } & 75.00 & 98.33 & 76.67 & 96.67 & 73.33 & 100.0 & 85.00 & 96.67 & 87.70 \\
\hline & \pm 7.63 & \pm 1.67 & \pm 4.94 & \pm 3.33 & \pm 4.21 & \pm 0.00 & \pm 2.23 & \pm 2.10 & \\
\hline & $(1.09)$ & $(1.50)$ & $(1.07)$ & $(1.48)$ & $(1.04)$ & $(1.55)$ & $(1.17)$ & $(1.45)$ & \\
\hline \multirow{3}{*}{ Manakamana-1 } & 71.67 & 98.33 & 73.33 & 95.00 & 73.33 & 98.33 & 80.00 & 95.00 & 85.62 \\
\hline & \pm 6.01 & \pm 1.67 & \pm 4.94 & \pm 3.41 & \pm 3.33 & \pm 1.66 & \pm 3.64 & \pm 2.23 & \\
\hline & $(1.02)$ & $(1.50)$ & $(1.03)$ & $(1.42)$ & $(1.03)$ & $(1.50)$ & $(1.11)$ & $(1.40)$ & \\
\hline \multirow{3}{*}{ Arun-4 } & 60.00 & 88.33 & 68.33 & 88.33 & 66.67 & 98.33 & 75.00 & 81.67 & 78.33 \\
\hline & \pm 7.74 & \pm 4.77 & \pm 5.42 & \pm 4.77 & \pm 6.66 & \pm 1.66 & \pm 3.41 & \pm 4.78 & \\
\hline & $(0.89)$ & $(1.28)$ & $(0.98)$ & $(1.28)$ & $(0.96)$ & $(1.50)$ & $(1.05)$ & $(1.16)$ & \\
\hline \multirow{3}{*}{ Arun-2 } & 58.33 & 93.33 & 58.33 & 85.00 & 61.67 & 95.00 & 80.00 & 90.00 & 77.70 \\
\hline & \pm 8.72 & \pm 3.33 & \pm 7.03 & \pm 5.62 & \pm 6.01 & \pm 2.23 & \pm 3.64 & \pm 5.16 & \\
\hline & $(0.87)$ & $(1.37)$ & $(0.87)$ & $(1.24)$ & $(0.91)$ & $(1.40)$ & $(1.11)$ & $(1.33)$ & \\
\hline \multirow{3}{*}{ Rampur composite } & 3.33 & 23.33 & 3.33 & 21.67 & 5.00 & 18.33 & $20.00^{\mathrm{b}}$ & 25.00 & 14.99 \\
\hline & \pm 3.33 & \pm 4.21 & \pm 2.10 & \pm 3.07 & \pm 3.41 & \pm 5.42 & \pm 5.77 & \pm 6.70 & \\
\hline & $(0.09)$ & $(0.49)$ & $(0.11)$ & $(0.47)$ & $(0.14)$ & $(0.39)$ & $(0.42)$ & $(0.48)$ & \\
\hline Grand Mean & 53.67 & 80.33 & 55.99 & 77.34 & 56.00 & 81.99 & 68.00 & 77.67 & \\
\hline CV (\%) & 14.5 & 11.5 & 17.6 & 13.2 & 18.3 & 13.1 & 12.5 & 11.6 & \\
\hline LSD & 0.33 & 0.41 & 0.41 & 0.45 & 0.43 & 0.47 & 0.34 & 0.39 & \\
\hline $\mathrm{P}$-value & $\leq 0.001$ & $\leq 0.001$ & $\leq 0.001$ & $\leq 0.001$ & $\leq 0.001$ & $\leq 0.001$ & $\leq 0.001$ & $\leq 0.001$ & \\
\hline
\end{tabular}

CV: coefficient variation; LSD: least significance difference; small alphabetic superscripts are significant by Duncan's multiple range test ( $\mathrm{p} \leq 0.001) ;$ numbers in the parenthesis are the arcsine square root transformation; value after \pm is the standard error of mean.

TABLE 2: Effect of weevil on spread of Aspergillus section flavi. on maize seeds from August to September, 2016.

\begin{tabular}{|c|c|c|c|c|c|c|c|c|c|}
\hline \multicolumn{10}{|c|}{ A. section flavus infestation (\%) } \\
\hline \multirow{2}{*}{ Weevil } & \multicolumn{8}{|c|}{ Days after inoculation } & \multirow{2}{*}{ Grand Mean } \\
\hline & 10 days & 12 days & 17 days & 19 days & 24 days & 26 days & 31 days & 33 days & \\
\hline \multirow{3}{*}{ Released } & $65.33^{\mathrm{a}}$ & $84.67^{\mathrm{a}}$ & $64.67^{\mathrm{a}}$ & $84.00^{\mathrm{a}}$ & $63.33^{\mathrm{a}}$ & $84.67^{\mathrm{a}}$ & $74.00^{\mathrm{a}}$ & $84.00^{\mathrm{a}}$ & 75.58 \\
\hline & \pm 8.32 & \pm 7.85 & \pm 8.44 & \pm 7.73 & \pm 7.84 & \pm 8.21 & \pm 6.15 & \pm 6.74 & \\
\hline & $(0.93)$ & $(1.33)$ & $(0.91)$ & $(1.31)$ & $(0.89)$ & $(1.32)$ & $(1.05)$ & $(1.31)$ & \\
\hline \multirow{3}{*}{ Not- released } & $42.00^{\mathrm{b}}$ & $76.00^{b}$ & $47.33^{b}$ & $70.67^{b}$ & $48.67^{\mathrm{b}}$ & $80.00^{\mathrm{b}}$ & $62.00^{b}$ & $70.67^{b}$ & 62.16 \\
\hline & \pm 6.48 & \pm 7.85 & \pm 6.43 & \pm 7.71 & \pm 6.60 & \pm 9.10 & \pm 7.18 & \pm 8.07 & \\
\hline & $(0.65)$ & $(1.13)$ & $(0.72)$ & $(1.05)$ & $(0.74)$ & $(1.22)$ & $(0.89)$ & $(1.02)$ & \\
\hline Grand Mean & 53.67 & 80.33 & 56.00 & 77.34 & 56.00 & 82.34 & 68.00 & 77.34 & \\
\hline CV (\%) & 18.4 & 8.9 & 10.4 & 12.1 & 15 & 7.4 & 9.4 & 12.9 & \\
\hline LSD & 0.24 & 0.17 & 0.14 & 0.23 & 0.13 & 0.07 & 0.14 & 0.24 & \\
\hline P-value & $\leq 0.001$ & $\leq 0.001$ & $\leq 0.001$ & $\leq 0.001$ & $\leq 0.01$ & $\leq 0.05$ & $\leq 0.001$ & $\leq 0.001$ & \\
\hline
\end{tabular}

CV: coefficient variation; LSD: least significance difference; alphabetic superscripts are significant at $\mathrm{p} \leq 0.001, \mathrm{p} \leq 0.01$ and $\mathrm{p} \leq 0.05$ by Duncan's multiple range test; numbers in the parentheses are the arcsine square root transformation; value after \pm is the standard error of mean.

\section{Results and Discussion}

\subsection{Laboratory Experiments}

3.1.1. Infestation of Different Varieties of Maize with Aspergillus section flavi. The infestation of different varieties of maize in this study is presented in Table 1 . There was highly significant difference among the varieties at 10 days to 33 days. The maximum infestation was obtained in Manakamana-3 at 26 days, i.e., $100 \pm 0.00$, while the lowest infestation, i.e., 3.33 \pm 3.33 and $3.33 \pm 2.10$, was obtained on Rampur composite on 10 days and 17 days, respectively. Rampur composite had less than $15 \%$ seeds infestation with $A$. section flavi and all other varieties with more than 50\% infestation distinguishing between highly resistant and susceptible varieties. Similar findings against $A$. section flavi were categorized by [24].

3.1.2. Effect of Weevil on Spread of Aspergillus section flavi on Maize Storage. The effect of weevil on spread of A. flavus is presented in Table 2 . There was significant difference 
TABLE 3: Damage of maize weevil, Sitophilus zeamais Motsch on maize varieties infestation with fungus under no choice condition at NAST, Lalitpur, Nepal, 2016.

\begin{tabular}{|c|c|c|c|}
\hline \multirow[t]{2}{*}{ Varieties } & \multicolumn{3}{|c|}{ Grain damage (Weight. basis) after 30 days of treatment (\%) } \\
\hline & Weevil Released & & Weevil Not- Released \\
\hline Manakamana-3 & $4.23 \pm 0.65(2.16)$ & & $0.00 \pm 0.00(0.70)$ \\
\hline Manakamana-1 & $2.94 \pm 0.40(1.85)$ & & $0.00 \pm 0.00(0.70)$ \\
\hline Arun-4 & $1.32 \pm 0.34(1.34)$ & & $0.00 \pm 0.00(0.70)$ \\
\hline Arun-2 & $1.08 \pm 0.39(1.24)$ & & $0.00 \pm 0.00(0.70)$ \\
\hline Rampur composite & $1.67 \pm 0.58(1.45)^{\mathrm{bc}}$ & & $0.00 \pm 0.00(0.70)^{\mathrm{d}}$ \\
\hline Grand Mean & 2.24 & & 0.00 \\
\hline $\mathrm{CV}(\%)$ & \multicolumn{3}{|c|}{15.9} \\
\hline LSD & \multicolumn{3}{|c|}{0.42} \\
\hline P-value & \multicolumn{3}{|c|}{$\leq 0.01$} \\
\hline
\end{tabular}

CV: coefficient variation; LSD: least significance difference; figures in the columns followed with alphabetic superscripts are significant at $\mathrm{p} \leq 0.01$ by Duncan's multiple range test; figures in the parentheses are the square root transformation; value after \pm is the standard error of mean.

among the weevil and the A. flavus infestation on each condition from 10 days to 33 days of study period. The highest infestations mean $(82.34 \%)$ was on 26 days while the lowest $(53.67 \%)$ was on 10 days. The highest mean contamination (75.58\%) was found under weevil present condition while it was lower $(62.16 \%)$ under absent condition. Maize weevil increases the efficacy of fungus infestation in their presence under storage. Maize weevils cause mechanical damage and increased moisture content. Insect infestation usually causes increased heating and moisture content in stored grains due to metabolic activity of the insects [28]. The number of spores carried by Maize weevils, whether internally, externally, or determined from whole body extracts, increased with the amount of time spent on the infected corn [18]. These authors reported that the maize weevil enhance growth of $A$. section flavi by increasing the area susceptible to fungal growth. $S$. zeamais was reported to contribute significantly to increase A. section flavi infection on corn ears by transporting spores and damaging corn kernels [29].

\subsubsection{Damage of Maize Weevil on Maize Varieties on Weight} Basis. The grain damage was significantly different $(\mathrm{P} \leq 0.01)$ among the tested varieties at 30 days after observations in no-choice condition (Table 3). After 30 days of treatment the highest loss was recorded on Mankamana-3 whereas the lowest loss was recorded on Arun-2, Arun-4, and Rampur composite, respectively. Rampur composite, Arun-2, and Arun- 4 were less affected by weevil. Yellow varieties were less susceptible to weevil damage as compared to white varieties [30].

\section{Conclusions}

In conclusion, the maximum infestation of the fungus was obtained on Manakamana-3 variety while the lowest infestation was obtained on Rampur composite. The highest mean contamination was found under presence of weevil while it was lower under absence of weevil. Manakamana-3 variety had the highest damage while Rampur composite, Arun-2, and Arun- 4 had the lowest damage. In presence of weevil, the infestation of the fungus increased and in their absence the infestation was low which signifies the role of weevil in fungal spread. All indices indicate that Rampur composite is best variety among the five tested varieties in terms of storage under the presence of fungus and weevils. This study also indicates ample scope for further study on different varieties of maize under several storage conditions for longer time period.

\section{Data Availability}

The data used to support the findings of this study are available from the corresponding author upon written request.

\section{Conflicts of Interest}

The authors declare that there are no conflicts of interest regarding the publication of this paper.

\section{Acknowledgments}

Institute of Agriculture and Animal Science, Nepal Academy of Science and Technology, and United Nations Development Program are highly acknowledged for providing laboratory facilities and financial support for this study.

\section{References}

[1] FAO, World Food and Agriculture, Food and Agriculture Organization of United States, Rome, Italy, 2013.

[2] C. Singh, Modern Techniques of Raising Field Crops, IBH Publishing Co.Pvt.Ltd, New Delhi, India, 2002.

[3] MoAD, Statistical Information on Nepalese Agriculture, Agribusiness Promotion and Statistics Division, Singh Darbar, Kathmandu, Nepal, 2015.

[4] A. R. Khosravi, M. Mansouri, A. R. Bahonar, and H. Shokri, "Mycoflora of maize harvested from Iran and imported maize," Pakistan Journal of Biological Sciences, vol. 10, no. 24, pp. 44324437, 2007.

[5] J. Aulakh and A. Regmi, "Post harvest food losses estimation," Developement of Consistent Methodology, p. 6, 2015. 
[6] T. Tefera, "Post harvest losses in African maize in the face of increasing food shortage," Food Security, vol. 6, no. 10, pp. 267277, 2012.

[7] APHILIS, "Losses Tables; Estimated postharvest losses (\%), 2014" http://www.aphlis.net/?form=home.

[8] L. Sherpa, N. G. Ojha, and A. R. Sharma, "Why farmers adpot or reject agricultural technology,A case study of improved maize and wheat varieties in the Ex-local largest area of Pakhribas Agriculture Center at Dhankuta. Dhankuta, Nepal," Pakhribas Agriculture Center, 1997.

[9] Y. D. Gharti Chhetri, "Efficacy of indegenous plant materials and modified storage structure to insect pests of maize during on farm storage," Journal of Institute of Agriculture abd Animal Science, vol. 27, pp. 69-76, 2006.

[10] C. P. Rugumamu, "Assesment of post harvest technologies and gender relations in maize loss reduction in Pangawe village eastern Tanzania," Tanzania Journal of Science, vol. 35, pp. 6776, 2012.

[11] J. L. Paes, L. R. D. Faroni, O. D. Dhingra, P. R. Cecon, and T. A. Silva, "Insecticidal fumigation action of mustard essential oil against Sitophilus zeamais in maize grains," Journal of Crop Protection, pp. 56-58, 2012.

[12] J. A. Ojo and A. A. Omoloye, "Rearing of maize weevil, Sitophilus zeamais on an artificial maize-cassava diet," Journal of Insect Science, pp. 1-2, 2012.

[13] S. S. Chu, S. S. Du, and Z. L. Liu, "Fumigant compounds from the essential oil of Chinese Blumea balsamifera leaves against maize weevil," Journal of Chemistry, pp. 1-7, 2013.

[14] S. Amaike and N. P. Keller, Aspergillus Flavus, University of Wisconsin, Madison, Wisconsin, USA, 2011.

[15] C. J. Alexopoulos and C. W. Mims, Introductory Mycology, Wiley Eastern Ltd, New Delhi, India, 1988.

[16] M. Micheal and P. Ensley, Understanding Fungal (Mold) Toxins (Mycotoxins) Plant Disease, Lincoln abd the United States Department of Agriculture, Lincoln, 2007.

[17] M. M. Sabbour, "Entomotoxicity assasy of two nano particle materials 1-(Al203 and TiO2) against Sitophilus oryzae under laboratory and store conditions in Egypt," Journal of Novel Applied Sciences, vol. 1, pp. 103-108, 2012.

[18] J. A. Beti, T. W. Phillips, and E. B. Smalley, "Effect of maize weevils (Coleoptera: Curculionidae) on production of aflatoxin B1 by Aspergillus flavus in stored corn," Journal of Economic Entomology, vol. 88, no. 6, pp. 1776-1782, 1995.

[19] S. Mohale, J. Allotey, and B. A. Siame, "Control of tribolium confusum J. Du Val by diatomaceous earth (Protect-IT) on stored groundnut (Arachis hypogea) and Aspergillus flavus Link spore dispersal," African Journal of Food Agriculture Nutrition and Developement, vol. 10, no. 6, pp. 2679-2694, 2010.

[20] R. M. Clear, S. K. Patrick, R. Wallis, and T. K. Turkington, "Effect of dry heat treatment on seed-borne Fusarium graminearum and other cereal pathogens," Canadian Journal of Plant Pathology, vol. 24, no. 4, pp. 489-498, 2002.

[21] J. A. Ojo and A. A. Amoloye, "Development and life history of sitophilus zeamais (coleoptera: curculionidae) on cereal crops," Advances in Agriculture, pp. 1-8, 2016.

[22] M. A. Klich and L. S. Lee, "Seed viability and aflatoxin production in individual cotton seed natirally contaminated with Aspergillus flavus," Journal of the American Oil Chemists' Society, p. 545, 2002.

[23] B. Hunsinger, B. A. Kamp, C. Kumala, and R. Böhm, "Comparison of the spread plate technique and the MPN-technique for the determination of viable colony counts in quantitative suspension tests to evaluate bactericidal and fungicidal activity of chemical disinfectants," in Proceedings of the In XIIth ISAH Congress, pp. 4-8, 2005.

[24] V. K. Mehan, D. McDonald, S. N. Nigam, and B. Lalitha, "Groundnut cultivars with seed resistant to invasion by Aspergillus flavus," ICRISAT, pp. 501-507, 1981.

[25] A. Prakash, J. Rao, I. C. Pasalu, and K. C. Mathur, Rice Storage and Insect Pest Management, B.R Publishing Corporation, New Delhi, India, 1987.

[26] P. W. Wambugu, E. O. Mathenge, Auma, and R. Havan, "Efficacy of traditional maize (Zea mays L.) seed storage methods in western Kenya," African Journal of Food and Agriculture, vol. 9, no. 4, pp. 1110-1128, 2009.

[27] K. A. Gomez and A. A. Gomez, Statistical Procedures for Agricultural Research, John Wiley and Sons, New York, NY, USA, 2nd edition, 1984.

[28] J. T. Mills, "Insect fungus association influencing seed detoration," Journal of Phytopathology, pp. 330-335, 1983.

[29] W. W. McMillan, N. W. Widstrom, D. M. Wilson, and R. A. Hill, "Transmission by maize weevils of Aspergillus flavus and its survival on selected corn hybrids," Journal of Economic Entomology, vol. 36, pp. 793-794, 1980.

[30] NMRP, Annual Report of National Maize Research Programme, NARC, Rampur, India, 2012. 


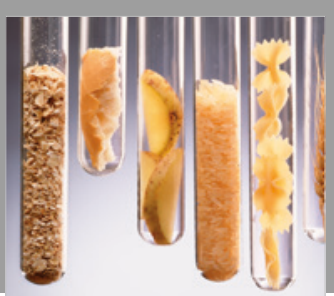

International Journal of Food Science

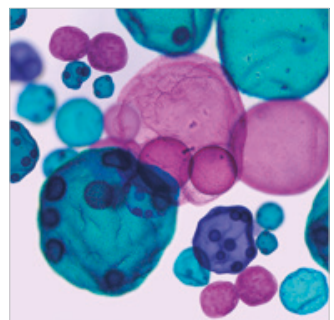

International Journal of Microbiology
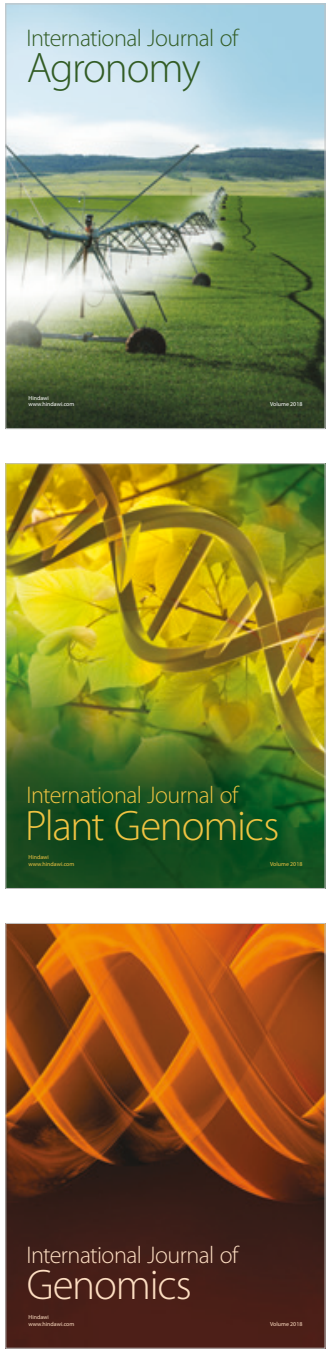

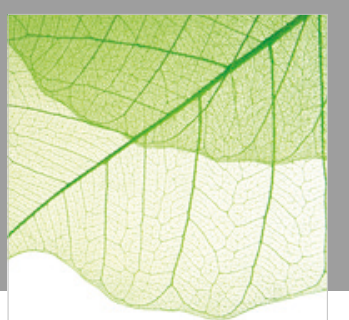

Journal of Botany
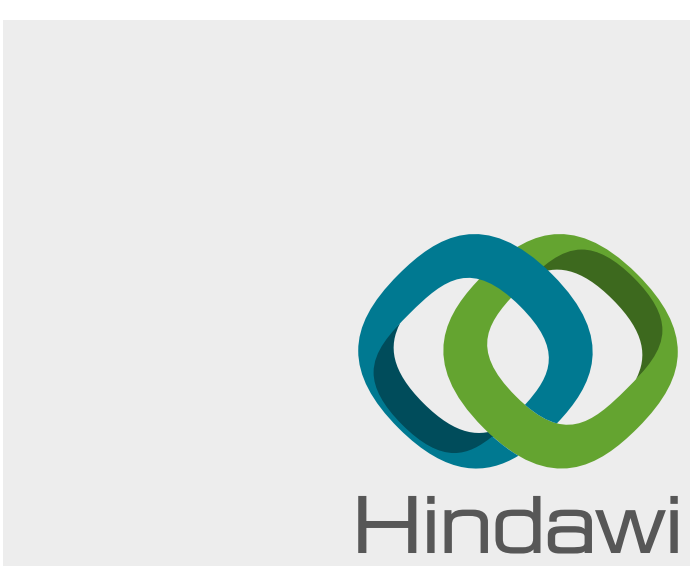

Submit your manuscripts at

www.hindawi.com
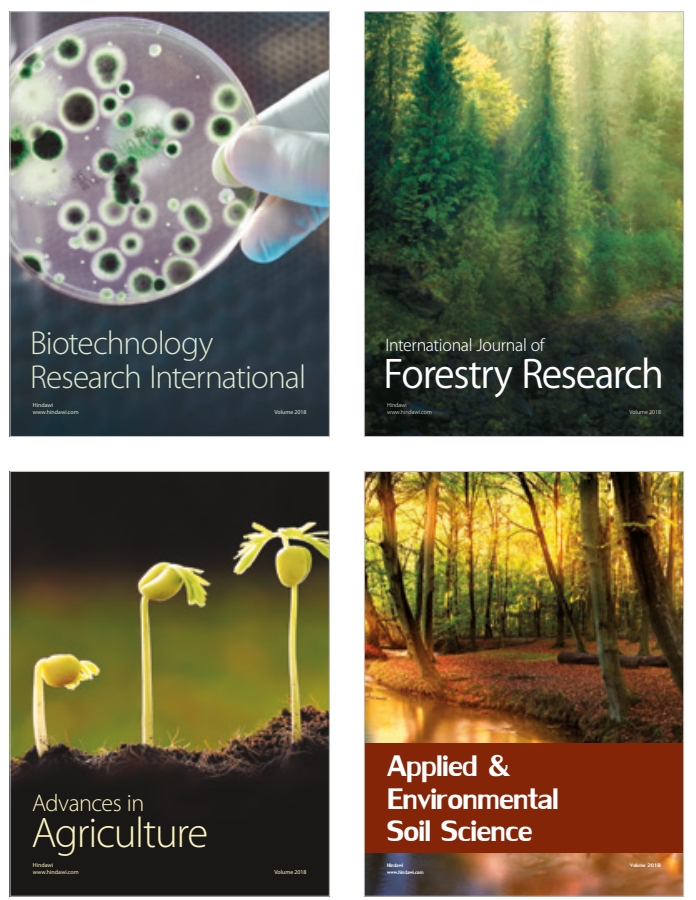

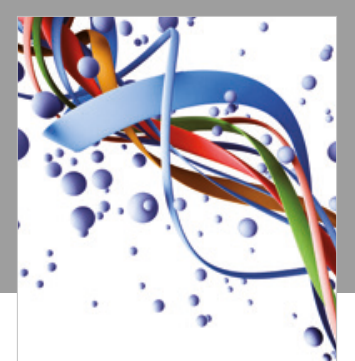

Scientifica

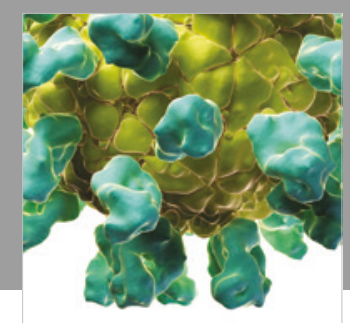

Veterinary Medicine International

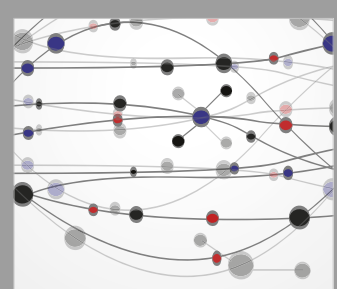

The Scientific World Journal
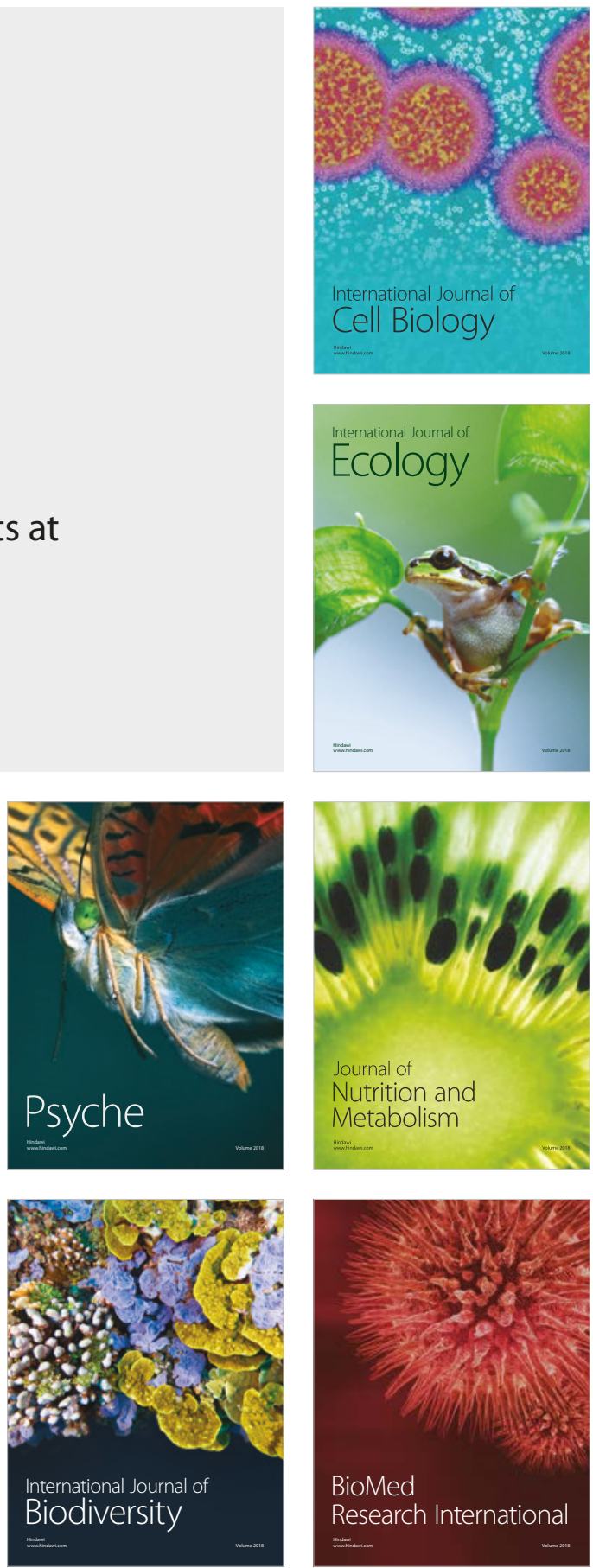